\title{
‘Sex Trafficking’ as Epistemic Violence
}

\author{
Ben Chapman-Schmidt
}

\begin{abstract}
While the American Allow States and Victims to Fight Online Sex Trafficking Act of 2017 (FOSTA) has been heavily criticised by researchers and activists for the harm it inflicts on sex workers, many of these critics nevertheless agree with the Act's goal of fighting sex trafficking online. This paper, however, argues that in American legal discourse, 'sex trafficking' refers not to human trafficking for sexual exploitation, but rather to all forms of sex work. As such, the law's punitive treatment of sex workers needs to be understood as the law's purpose, rather than an unfortunate side effect. This paper also demonstrates how the discourse of 'sex trafficking' is itself a form of epistemic violence that silences sex workers and leaves them vulnerable to abuse, with FOSTA serving to broaden the scope of this violence. The paper concludes by highlighting ways journalists and academic researchers can avoid becoming complicit in this violence.
\end{abstract}

Keywords: human trafficking, sex work, human rights, law enforcement, governmentality, postcolonial theory

Suggested citation: B Chapman-Schmidt, "Sex Trafficking" as Epistemic Violence', Anti-Trafficking Review, issue 12, 2019, pp. 172-187, www.antitraffickingreview.org

\section{Introduction}

On 11 April 2018, the United States signed into law the Allow States and Victims to Fight Online Sex Trafficking Act of 2017 (FOSTA), with the stated purpose of ending 'sex trafficking' on the internet. There has been widespread criticism of this bill from researchers and activists, both for the way it undermines free speech on the internet and for the likelihood that it will negatively impact the health and safety of sex workers. However, even among these critical, sex worker-supportive outlets, many have spoken positively about 
the Act's stated purpose of targeting 'sex trafficking' online. ${ }^{1}$ These researchers and journalists tend to depict the negative outcomes of FOSTA as consequences of overreach or an excess of zeal; for them, the campaign against 'sex trafficking' itself is both a worthy cause and compatible with the rights of sex workers.

This paper challenges that position. Drawing on an analysis of American legislation and a review of the existing literature on human trafficking and sex work, it argues that in American legal discourses, 'sex trafficking' refers not to human trafficking for sexual exploitation but rather to the traffic in sex-a definition which includes all forms of sex work. As such, the negative consequences of FOSTA for sex workers are, in fact, the intended outcome of this anti-'sex trafficking' law. This paper further argues that the propagation of the term 'sex trafficking', and its displacement of both the language and social spaces used by sex workers, constitutes a form of epistemic violence, and that this epistemic violence leads, in turn, to an increase in physical violence against sex workers. FOSTA thus represents an attempt to entrench and advance this form of epistemic violence. The paper concludes by exploring the role that journalists and researchers play in propagating this epistemic violence and by suggesting strategies that might be adopted to resist it.

\section{What is 'Sex Trafficking'?}

Many researchers and journalists appear to use the term 'sex trafficking' as a shorthand for human trafficking for sexual exploitation. However, in the context of United States law, the term 'sex trafficking' is given meaning by the Trafficking Victims Protection Act of 2000 (TVPA), which defines it as: 'The recruitment, harboring, transportation, provision, or obtaining of a person for the purpose of a commercial sex act. ${ }^{2}$ Notably absent from this definition

1 See for example A Romano, 'A New Law Intended to Curb Sex Trafficking Threatens the Future of the Internet as We Know It', Vox, 13 April 2018, https://www.vox.com/culture/2018/4/13/17172762/fosta-sesta-backpage230-internet-freedom; E Goldman, 'Balancing Section 230 and Anti-Sex Trafficking Initiatives', Legal Studies Research Papers Series, No. 2017-17, Santa Clara University School of Law, Rochester, NY, 30 November 2017, http:// papers.ssrn.com/abstract=3079193; E Goldman, 'Sex Trafficking Exceptions to Section 230', Legal Studies Research Papers Series, No. 2017-13, Santa Clara University School of Law, Rochester, NY, 19 September 2017, http:// papers.ssrn.com/abstract=3038632; A Glaser, 'After Backpage', Slate, 27 April 2018, https://slate.com/technology/2018/04/after-backpage-and-sesta-sexworkers-worry-theyll-have-to-return-to-the-streets.html.

2 Victims of Trafficking and Violence Protection Act of 2000. Public Law 106-386. U.S. Statutes at Large 114 (2000): 1463-1548. Cited below as TVPA 2000. Sec. 103(9). 
is any requirement for a 'means', or even for 'exploitation'. In other words, according to the TVPA, 'sex trafficking' is simply involvement in any aspect of personnel recruitment for the sex industry. Moreover, this definition has subsequently been expanded to include 'patronizing or soliciting', 3 meaning that in the United States, 'sex trafficking' is legally defined to include the act of purchasing sex. This definition is clearly at odds with the idea of human trafficking for sexual exploitation found in the UN Trafficking Protocol. Instead, it appears to be based on a literal reading of the term 'sex trafficking': the illicit trade in commercial sex. ${ }^{4}$

It is important here to note that the TVPA does not actually criminalise 'sex trafficking'. Instead, it criminalises 'severe forms of trafficking in persons', which it defines as:

(A) Sex trafficking in which a commercial sex act is induced by force, fraud, or coercion, or in which the person induced to perform such act has not attained 18 years of age; or

(B) the recruitment, harboring, transportation, provision, or obtaining of a person for labor or services, through the use of force, fraud, or coercion for the purpose of subjection to involuntary servitude, peonage, debt bondage, or slavery. ${ }^{5}$

Taken together, these two sections suggest that the American definition of 'severe forms of trafficking in persons' is relatively close to the definition of 'trafficking in persons' found in the UN Trafficking Protocol, in that it both includes forms of exploitation not related to sex and does not include sex work practices by consenting adults. ${ }^{6}$ However, the fact that the TVPA does

3 Justice for Victims of Trafficking Act of 2015, Pub. L. No. 114-22, 129 Stat. 227267 (2015) ('TVPRA 2015'), Sec. 108(c).

4 The usage of the term 'trafficking' here appears to follow this definition given by the Oxford English Dictionary: 'Dealing or bargaining in something which should not be made the subject of trade'. See 'Traffic, N.', OED Online, Oxford University Press, http://www.oed.com/view/Entry/204333; see also A E Cassimatis, C Drummond and K Greenwood, 'Traffic in Arms', Max Planck Encyclopedia of Public International Law, Max Planck Foundation for International Peace and the Rule of Law, 2016, http://opil.ouplaw.com/view/10.1093/ law:epil/9780199231690/law-9780199231690-e98 for a discussion of the distinction between 'arms trade' and 'arms trafficking'.

TVPA 2000, Sec. 103(8).

${ }^{6}$ This two-tiered definition emerged both from the messy legislative process of merging competing anti-trafficking bills in 1999, and the on-going battle over how to define 'human trafficking' that also led to the ambiguity found in the UN definition. See, for example: J A Chuang, 'Rescuing Trafficking from Ideological Capture: Prostitution reform and anti-trafficking law and policy', University of Pennsylvania Law Review, vol. 158, no. 6, 2010, pp. 1655-1728; B Sullivan, 'Trafficking in Women: Feminism and new international law', International Feminist Journal of Politics, vol. 5, no. 1, 2003, pp. 67-91, https://doi.org/10.1080/ 1461674021000056773. 
not make 'sex trafficking' a criminal offense at the federal level is somewhat misleading. In the United States, most criminal law enforcement is conducted at the state level ${ }^{7}$ and sex work is already illegal in every state but Nevada meaning that any attempt to criminalise 'sex trafficking' at the federal level would have been largely redundant.

This does not mean that the introduction of the 'sex trafficking' paradigm into the American legal system did not have an impact at the state level. Subsequent to the passage of the TVPA, some states did begin to target sex workers' clients for criminal sanction, on the theory that these individuals were 'sex traffickers'. ' Others, however, have deliberately decided not to target the buyers of sex, under the logic that targeting sex workers does more to diminish the availability of commercial sex. ${ }^{10}$ Notably, despite the fact that, in the eyes of the law in the United States, all purchases of commercial sex are 'sex trafficking', no states have ended the penal sanctioning of sex workers themselves, except for cases where the individuals involved are minors. ${ }^{11}$ In some cases, these sanctions have simply been rebranded. The State of New York decided that sex workers are, in fact, victims of 'sex trafficking' - and subsequently established diversionary courts where they could be suitably tried

As measured by the relative number of prisoners in the state prisons $(1,316,205$ in 2016) compared to the number of prisoners in federal prisons $(189,192$ in 2016), on the basis that prison populations will provide a (very rough) proxy for law enforcement activities. Statistics from E A Carson, 'Prisoners in 2016', Bulletin, US Department of Justice, Bureau of Justice Statistics, January 2018, p. 4.

8 Even in Nevada, sex work is only legal in certain (largely rural) counties, and is criminalised in the major metropolitan areas. See R Weitzer, 'The Movement to Criminalize Sex Work in the United States', Journal of Law and Society, vol. 37, no. 1, 2010, pp. 61-84, https://doi.org/10.1111/j.1467-6478.2010.00495.x; O Myers, 'Sex for Sale: The implications of Lawrence and Windsor on prostitution in the United States', Tennessee Journal of Race, Gender, \& Social Justice, vol. 5, issue 1, 2016, pp. 93-112; K Lerum and B G Brents, 'Sociological Perspectives on Sex Work and Human Trafficking', Sociological Perspectives, vol. 59, no. 1, 2016, pp. 17-26, https://doi.org/10.1177/0731121416628550.

9 E Bernstein, 'Carceral Politics as Gender Justice? The "traffic in women" and neoliberal circuits of crime, sex, and rights', Theory and Society, vol. 41, no. 3, 2012, pp. 233-59, https://doi.org/10.1007/s11186-012-9165-9.

${ }^{10} \mathrm{~N}$ Benitez et al., 'Prostitution and Sex Work Annual Review', Georgetown Journal of Gender and the Law, vol. 19, 2018, pp. 339-40.

11 For examples of the latter, see, for instance: L Territo and N Glover, Criminal Investigation of Sex Trafficking in America, CRC Press, Boca Raton, FL, 2013, pp. $67-72$. 
as victims. ${ }^{12}$ In Houston, the police have claimed that arresting and prosecuting sex workers is intended to help them escape from trafficking. ${ }^{13}$ In other cases, there has been movement in the opposite direction. Rhode Island, where previously only solicitation had been illegal, criminalised the sale of sex in $2009 .{ }^{14}$ Much of the driving force for this change came from the local activist Donna Hughes,${ }^{15}$ who has publically stated that she views 'sex trafficking' and sex work as one and the same. ${ }^{16}$ The cumulative effect of these laws is that in the American criminal justice system, sex workers are treated as being equallyif not more-culpable as their clients in the crime of 'sex trafficking'.

This is the context in which we should view the Allow States and Victims to Fight Online Sex Trafficking Act of 2017 (FOSTA). It should also be noted that the internet, which has enabled the proliferation of alternative modes of sexuality, has long attracted the ire of activists in religiously conservative countries such as Pakistan, ${ }^{17}$ Egypt,${ }^{18}$ and the United States. ${ }^{19}$ Activities targeted by these activists have certainly not been limited to sex work; the groups and

12 A Ray and E Caterine, Criminal, Victim or Worker? The effects of New York's buman trafficking intervention courts on adults charged with prostitution-related offences, Red Umbrella Project, New York, October 2014; A Gruber, A J Cohen, and K Mogulescu, 'Penal Welfare and the New Human Trafficking Intervention Courts', Florida Law Review, vol. 68, 2016, pp. 1333-1402, https://doi.org/10.2139/ ssrn.2776870; A J Cohen and A Gruber, 'Governance Feminism in New York's Alternative "Human Trafficking Intervention Courts", SSRN Scholarly Paper, Social Science Research Network, Rochester, NY, 2 March 2017, https://papersssrn-com.virtual.anu.edu.au/abstract=2926393; M Dank, J Yahner, and L Yu, 'Consequences of Policing Prostitution', Urban Institute, April 2017.

${ }_{13}$ J Musto, Control and Protect: Collaboration, carceral protection, and domestic sex trafficking in the United States, University of California Press, Berkeley, CA, 2016, pp. xiixiii.

14 Benitez et al., p. 335.

15 E O'Brien, S Hayes, and B Carpenter, The Politics of Sex Trafficking: A moral geography, Palgrave Macmillan, Basingstoke, Hampshire, 2013, p. 16.

16 K J Lopez and D Hughes, 'The New Abolitionist Movement: Donna Hughes on progress fighting sex trafficking', National Review, 26 January 2006, retrieved 7 November 2018, https://www.nationalreview.com/2006/01/new-abolitionistmovement-interview/.

17 U Ali and H B Munawar, 'Internet Landscape of Pakistan 2017', Bytes for All, Pakistan, 2017, https://bytesforall.pk/sites/default/files/Internet_ Landscape_Pakistan_2017.pdf.

$18 \mathrm{~J}$ Zittrain and J Palfrey, 'Internet Filtering: The politics and mechanisms of control', in R Deibert, J Palfrey, R Rohozinski and $\mathrm{K}$ Zittrain (eds.), Access Denied: The practice and policy of global internet filtering, MIT Press, Cambridge, MA, 2008, p. 32.

19 P Franzese et al., 'Censorship on the Internet: Do obscene or pornographic materials have a protected status?', Fordham Intellectual Property, Media and Entertainment Law Journal, vol. 5, no. 2, 1995, pp. 279-327. 
individuals that collaborated on FOSTA, for example, have also been involved in efforts to crack down on pornography ${ }^{20}$ as well as to marginalise and stigmatise LGBTIQ individuals. ${ }^{21}$ In the United States, however, efforts by moral entrepreneurs to censor sections of the internet they find objectionable have been stymied by Section 230 of the Communications Act of 1934, a law that holds that, 'No provider or user of an interactive computer service shall be treated as the publisher or speaker of any information provided by another information content provider. ${ }^{22}$ This provision made it possible for websites like eBay, Facebook, and Google to host user-generated content without worrying that they would face civil and criminal liability if their users used their platforms to, for example, negotiate the sale of sex. ${ }^{23}$ One website in particular - the classifieds website Backpage.com (Backpage)—became wellknown as a platform for sex workers to negotiate with clients, and the owners of this website subsequently made heavy use of Section 230 to defend themselves from legal and economic sanctions from officials who saw it as a front for 'sex trafficking'. 24

${ }^{20}$ The National Center on Sexual Exploitation, which Romano characterises as 'one of the bill's main supporters', uses misleading 'research reports' to fabricate a false medical consensus about the harms of pornography. See Romano; National Center on Sexual Exploitation, 'Pornography: A public health crisis', National Center on Sexual Exploitation, 1 April 2015, https://endsexualexploitation.org/ publichealth/.

21 Mimi Walters, the Congressional Representative who introduced the critical amendment to FOSTA allowing for the targeting of websites with criminal and civil sanctions, supported California's infamous proposition 8 , as well as voting to secure the right for federal contractors to discriminate against LGBT individuals. See 'Endorsements', Yes on 8: Protect Marriage, ProtectMarriage.com, 4 November 2008, https://web.archive.org/web/ 20081104193847/http://www.protectmarriage.com/endorsements/officials; S Pathé, '7 Republicans Flipped Their Vote on LGBT Amendment, Setting Them Up for Attack,' Roll Call, 19 May 2016, https://www.rollcall.com/news/politics/ democrats-pounce-vulnerable-republicans-suspected-switching-vote-lgbtprotections.

22 Communications Act, U.S. Code 47 (1934), sec. 201 et seq, as amended by the Telecommunications Act of 1996. Public Law 104-104. U.S. Statutes at Large 110 (1996): 56-161. Title V-Obscenity and Violence ('Communications Decency Act of 1996'), sec. 509.

${ }^{23}$ D S Ardia, 'Free Speech Savior or Shield for Scoundrels: An empirical study of intermediary immunity under section 230 of the Communications Decency Act', Loyola of Los Angeles Law Review, vol. 43, 2010, pp. 373-506; M A Lemley, 'Rationalizing Internet Safe Harbors', Journal on Telecommunications \& High Technology Law, vol. 6, 2007, pp. 101-120.

24 A F Levy, 'The Virtues of Unvirtuous Spaces', Wake Forest Law Review, vol. 52, 2017, pp. 403-434; N Tischler, 'Free Speech under Siege: Why the vitality of modern free speech hinges on the survival of section 230 of the Communications Decency Act: Notes \& Comments', Temple Political \& Civil Rights Law Review, vol. 24, 2014, pp. 277-300. 
The courts eventually found that Backpage did not have Section 230 immunity, ${ }^{25}$ and more recently, its CEO pleaded guilty to facilitating prostitution and to money laundering. ${ }^{26}$ Nevertheless, Backpage's long history of openly advertising sexual services in the face of a governance regime that defined all such services as 'sex trafficking' led to a movement by moral entrepreneurs to limit the scope of Section 230. This movement culminated in the drafting of both the original version of FOSTA, introduced in the United States House of Representatives on 3 April 2017, and the Stop Enabling Sex Traffickers Act of 2017 (SESTA), introduced in the United States Senate on 1 August 2017. ${ }^{27}$

FOSTA (in the version sent to the Senate) created a new criminal law targeting 'whoever uses or operates a facility or means of interstate or foreign commerce or attempts to do so with the intent to promote or facilitate the prostitution of another person'. ${ }^{28}$ This bill, as the inclusion of 'sex trafficking' in its title would suggest, broadly targeted all websites facilitating sex work. However, to be targeted for sanctions, a prosecutor would need to demonstrate that this facilitation was intentional. SESTA, on the other hand, simply declared that Section 230 would not apply to the US Code, Section 1591_'Sex trafficking of children or by force, fraud, or coercion. ${ }^{29}$ Prosecutors would thus not need to show that the website intended to host the offending content, but such

${ }^{25}$ S J Daheim, 'How the Washington State Supreme Court Wrongly Applied the Communications Decency Act in Village Voice, and What It Means for Internet Service Providers', Washington Journal of Law, Technology \& Arts, vol. 12, no. 1, 2016, pp. 77-94.

${ }^{26}$ M Ehrenkranz, 'Backpage CEO Pleads Guilty and the Website Will Be Permanently Shut Down', Gizmodo, 13 April 2018, https://gizmodo.com/ backpage-ceo-pleads-guilty-and-the-website-will-be-perm-1825236756.

27 This according to two of the primary sponsors of SESTA, Rob Portman and Claire McCaskill. See 'FACT SHEET: Portman's Stop Enabling Sex Traffickers Act', Rob Portman: United States Senator for Ohio, 14 March 2018, https:// www.portman.senate.gov/public/index.cfm/press-releases?ID=CCBC2A795C48-4C53-8C9B-12D35277E6B4; 'McCaskill, Bipartisan Group, Introduce Legislation to "Stop the next Backpage", Ensure Justice for Victims of Sex Trafficking', Claire McCaskill: An Independent Voice for Missouri, 1 August 2017, https://www.mccaskill.senate.gov/media-center/news-releases / mccaskill-bipartisan-group-introduce-legislation-to-stop-the-next-backpageensure-justice-for-victims-of-sex-trafficking.

28 U.S. Congress, House, Allow States and Victims to Fight Online Sex Trafficking Act of 2017, HR 1865, $115^{\text {th }}$ Cong., $2^{\text {nd }}$ session, introduced in House 3 April 2017, as reported in House 20 February 2018, https://www.congress.gov/bill/115thcongress/house-bill/1865/text/rh.

${ }^{29}$ U.S. Congress, Senate, Stop Enabling Sex Traffickers Act of 2017, SR 1693, $115^{\text {th }}$ Cong., $2^{\text {nd }}$ session, introduced in Senate 1 August 2017, https:// www.congress.gov/bill/115th-congress/house-bill/1865/text/rh. 
prosecutions would be limited to cases where the individuals involved were below the age of eighteen. FOSTA was then subsequently amended to include SESTA's limitations of Section 230, and it was this version of FOSTA (sometimes referred to as 'FOSTA-SESTA')—one which requires neither intent on behalf of the content host nor that the individual involved be below the age of 18 - that was ultimately signed into law.

\section{'Sex Trafficking' as Epistemic Violence}

For libertarians, ${ }^{30}$ civil liberties advocates, ${ }^{31}$ and proponents of a free and open internet, the finalised version of FOSTA thus represents the worst of both worlds. The Electronic Frontier Foundation (EFF) referred to this version as 'A bad bill that turned into a worse bill', and noted that, 'Today was a dark day for the Internet'; ${ }^{32}$ it has subsequently launched a lawsuit to have the law declared unconstitutional. ${ }^{33}$ However, even as the EFF and others-such as Human Rights Watch ${ }^{34}$ — seek an injunction against the law, its effects are already being felt. Reddit has shut down social spaces ('subreddits') for sex workers, such as r/escorts; Instagram has increased scrutiny over hashtags used by sex workers; and Patreon, a site for content creators to seek funders, has shut down accounts linked to adult content. ${ }^{35}$ Notably, these latter two sites are nothing like Backpage: they do not offer infrastructure facilitating

${ }^{30}$ E Nolan Brown, 'FOSTA and the Federal Seizure of Backpage.com', CATO Institute Daily Podcast, 12 April 2018, https://www.cato.org/multimedia/catodaily-podcast/fosta-federal-seizure-backpagecom.

31 I Thompson, 'Congress Proposes to Fight Online Trafficking by Harming Sex Workers', American Civil Liberties Union, 16 March 2018, https:// www.aclu.org/blog/criminal-law-reform/congress-proposes-fight-onlinetrafficking-harming-sex-workers.

32 E Harmon, 'How Congress Censored the Internet', Electronic Frontier Foundation, 21 March 2018, https://www.eff.org/deeplinks/2018/03/howcongress-censored-internet.

33 D Greene, 'EFF Sues to Invalidate FOSTA, an Unconstitutional Internet Censorship Law', Electronic Frontier Foundation, 28 June 2018, https:// www.eff.org/deeplinks/2018/06/eff-sues-invalidate-fosta-unconstitutionalinternet-censorship-law.

34 M Locklear, 'EFF and Human Rights Groups Sue to Have FOSTA Declared Unconstitutional', Engadget, 29 June 2018, https://www.engadget.com/2018/ 06/29/eff-human-rights-groups-sue-fosta-unconstitutional.

35 T Horn, 'Sex-Worker Advocates Sue Over Internet "Censorship" Law', Rolling Stone, 30 June 2018, https://www.rollingstone.com/culture/culture-features/ sex-worker-advocates-lawsuit-internet-censorship-sesta-fosta-666783/. Horn claimed that Reddit had banned r/Sexworkers, but as of the time of writing, this subreddit is still available. Others, such as $\mathrm{r}$ /Hookers and r/Escorts have been confirmed as banned. 
commercial sex but rather social and artistic spaces. FOSTA has also led to the cancellation of the largest sex worker conference in the US (out of concern that some of the workshops would now be illegal), ${ }^{36}$ and the shutting down of sex worker outreach services. ${ }^{37}$ That these are not unexpected consequencesthe House and Senate heard multiple testimonies about the likely outcomes of these measures ${ }^{38}$ — suggests that they were also not unintended, and that the shuttering of expressive and communicative spaces for sex workers was a feature of the bill, not a bug. After all, these spaces are, in the language of the American legal system, 'facilitating sex trafficking'.

FOSTA, then, aims not only to target sex workers with criminal sanctions, but also to cut off the means they have to express themselves online-in effect, to silence them, along with the people and organisations that support them. Silencing groups that provide assistance to sex workers has been a longstanding US government policy: both TVPA (as amended in 2003) and the President's Emergency Plan for AIDS Relief (PEPFAR, also passed in 2003) contained language requiring any organisation receiving funding to have

${ }^{36}$ According to the conference website; see Desiree Alliance, 'Conference', Desiree Alliance, http://desireealliance.org/conference/. However, in an interview with Courtney Trouble, Cris Sardina, the director at the Desiree Alliance, noted that the shutdown was also motivated in part by a fear of Immigration and Customs Enforcement (ICE) raids. See C Trouble, 'Largest Sex Worker Conference in the US Is Canceled Amid FOSTA Fears', Motherboard, 15 June 2018, https:// motherboard.vice.com/en_us/article/wjbkp9/desiree-conference-canceledfosta-sesta-sex; see also Global Network of Sex Work Projects, 'Largest Sex Worker Conference in the USA Is Cancelled Due to Threat from FOSTA-SESTA', NSWP, 22 June 2018, http://www.nswp.org/news/largest-sex-workerconference-the-usa-cancelled-due-threat-fosta-sesta.

37 Note that the primary reason given by SWOP Sacramento in March 2018 for suspending many of its outreach services was the threat posed by Bill SB 1204 in California. See Swop Sacramento, Twitter post, 31 March 2018, https:// twitter.com/SwopSacramento/status/980104504422031360. However, the organisation also noted the 'recent political climate', and Kristen DiAngelo, the executive director of SWOP Sacramento, has elsewhere elaborated that this refers to the result of FOSTA emboldening police and prosecutors to target sex workers. See T Clark-Flory, 'Facing SESTA and Political Threats, Sex Worker Organizations Brace for Fallout', The Slot, 6 April 2018, https:// theslot.jezebel.com/facing-sesta-and-political-threats-sex-worker-organiza1824257817.

38 See, for example, Goldman, 'Balancing Section 230 and Anti-Sex Trafficking Initiatives'; Goldman, 'Sex Trafficking Exceptions to Section 230'; American Civil Liberties Union, 'ACLU Vote Recommendation on FOSTA', ACLU, 20 March 2018, https://www.aclu.org/letter/aclu-vote-recommendation-fosta; S E Boyd, 'The Views of the Department of Justice on H.R. 1865, the "Allow States and Victims to Fight Online Sex Trafficking Act of 2017"', US Department of Justice, Office of Legislative Affairs, 27 February 2018, https:// assets.documentcloud.org/documents / 4390361 /Views-Ltr-Re-H-R-1865Allow-States-and-Victims.pdf. 
an explicit policy opposing prostitution, ${ }^{39}$ mirroring the language used in a 2002 National Security Presidential Directive. ${ }^{40}$ With this requirement for an 'anti-prostitution pledge', the US government sought to control not only how public funds were used, but also how the organisations receiving those funds think and express themselves at all times. This requirement remained in effect for all grant recipients until its application to American organisations was struck down by the Supreme Court as unconstitutional in 2013; it remains in effect, however, for foreign grant recipients. ${ }^{41}$ Similarly, the US government controls a very significant portion of the available research funding in the social sciences; here, too, it works to ensure that funds for research on 'trafficking' are directed toward research that supports the 'sex work as sex trafficking' paradigm and away from research that supports sex workers' rights. ${ }^{42}$ Researchers who do receive funding from the US government are not only unable to advocate for sex workers, but also are often unable to even use terms such as 'sex work' or 'sex worker' in any of their reports. ${ }^{43}$ These efforts

39 See, for example, N Franck Masenior and C Beyrer, 'The US Anti-Prostitution Pledge: First Amendment challenges and public health priorities', PLOS Medicine, vol. 4, no. 7, 24 July 2007, https://doi.org/10.1371/journal.pmed.0040207; R Moshman, 'Anti-Prostitution Pledge: Limiting speech and development litigation updates', Sustainable Development Law \& Policy, vol. 6, 2005, pp. 66-67.

$40 \mathrm{~J}$ L Musto, 'What's in a Name?: Conflations and contradictions in contemporary U.S. discourses of human trafficking', Women's Studies International Forum, vol. 32, no. 4, 2009, pp. 281-287, https://doi.org/10.1016/j.wsif.2009.05.016.

${ }^{41}$ Note that, despite this ruling, the government continued to apply the pledge to US organisations operating abroad until this practice was struck down in 2015. See S Krueger, 'A Striking Defeat for U.S. Government's Anti-Prostitution Pledge', Open Society Foundations, 24 February 2015, https:// www.opensocietyfoundations.org/voices/striking-defeat-us-government-s-antiprostitution-pledge.

$42 \mathrm{~J}$ Dorf, Sex Worker Health and Rights: Where is the funding?, Sexual Health and Rights Project, Open Society Institute, June 2006, https:// www.opensocietyfoundations.org/sites/default/files/where.pdf; R Weitzer, 'The Social Construction of Sex Trafficking: Ideology and institutionalization of a moral crusade', Politics \& Society, vol. 35, no. 3, 2007, pp. 447-475, https:// doi.org/10.1177/0032329207304319; A Forbes, 'Speaking of Sex Workers: How suppression of research has distorted the United States' domestic HIV response', Reproductive Health Matters, vol. 23, no. 45, 2015, pp. 21-29, https:// doi.org/10.1016/j.rhm.2015.06.008; J Fitzgerald, 'How the Government and the Christian Lobby Quash Real Research on Sex Workers', Pacific Standard, 16 June 2015, https:/ / psmag.com/news/government-christian-lobby-quashes-realresearch-on-sex-workers.

43 Forbes; E C M Kinney, 'Appropriations for the Abolitionists: Undermining effects of the U.S. mandatory anti-prostitution pledge in the fight against human trafficking and HIV/AIDS recent development', Berkeley Journal of Gender, Law \& Justice, vol. 21, 2006, pp. 158-194, https://doi.org/10.15779/Z38S17SS0N; M R Decker, C Beyrer, and S G Sherman, 'Ending the Invisibility of Sex Workers in the US HIV/AIDS Surveillance and Prevention Strategy', AIDS, vol. 28, no. 15, 24 September 2014, pp. 2325-2327, https://doi.org/10.1097/ QAD.0000000000000411. 
form part of a broader effort to delegitimise and stigmatise researchers who advocate for sex workers' rights, with government-sponsored anti-sex worker activists claiming that these researchers are 'sex radicals" ${ }^{\text {' }}$ or that they are part of 'pro-prostitution industry groups'. ${ }^{45}$

Taken together, these efforts represent an attempt to silence any discussions of sex work and to replace them with discussions of 'sex trafficking'. This suggests that the effort to eradicate the term 'sex work' needs to be understood as an example of what Gayatri Spivak calls 'epistemic violence'. Spivak is primarily interested in the subaltern subject (subjects who are both colonised and non-elite, and who are thus fully cut off from access to hegemonic culture), arguing that they cannot 'speak', even through the language of an elite academic interpreter, as the epistemic violence of imperialism has deprived them of the tools they need to express themselves. ${ }^{46}$ Changing the episteme thus deprives marginalised subjects of their voices, and forces them to speak in the language of their oppressors.

Sex workers are not all (although certainly many are) subaltern in the sense that Spivak used the term: many, in particular those in wealthy Anglo-European countries, retain access in some way to hegemonic cultural power. However, sex workers do remain very clearly marginalised, both by professional stigma and by legal sanctions. Historically, the language used to refer to sex workers has served to amplify this stigma as it has allowed them to be represented only as 'prostituted women' (i.e. unwilling victim objects), ${ }^{47}$ or else as 'whores'

44 Donna Hughes as cited in R Weitzer, 'Resistance to Sex Work Stigma', Sexualities, vol. 21, no. 5-6, 2017, p. 10, https://doi.org/10.1177/1363460716684509.

45 J G Raymond, 'Prostitution as Violence Against Women: NGO stonewalling in Beijing and elsewhere', Women's Studies International Forum, vol. 21, no. 1, 1998, p. 3, https://doi.org/10.1016/S0277-5395(96)00102-1.

${ }^{46}$ G Chakravorty Spivak, 'Can the Subaltern Speak?', in C Nelson and L Grossberg (eds.), Marxism and the Interpretation of Culture, University of Illinois Press, Urbana, IL, 1988, pp. 281, 310; M Foucault, Madness and Civilization: A history of insanity in the age of reason, trans. Richard Howard, 1961; repr., Vintage Books, New York, NY, 1965.

47 See, for example, H Van Bavel, 'Beyond Exploitation: Towards a nuanced understanding of agency for adolescent female sex workers-evidence from Zanzibar and Morogoro', Culture, Health \& Sexuality, vol. 19, no. 1, 2017, p. 76, https://doi.org/10.1080/13691058.2016.1207253; G Ellison, 'Who Needs Evidence? Radical feminism, the Christian right and sex work research in Northern Ireland', in S Armstrong, J Blaustein, and A Henry (eds.), Reflexivity and Criminal Justice: Intersections of policy, practice and research, Palgrave Macmillan, London, 2017, pp. 291-292; S Huschke, 'Victims Without a Choice? A critical view on the debate about sex work in Northern Ireland', Sexuality Research and Social Policy, vol. 14, no. 2, 2017, pp. 192-205, https://doi.org/10.1007/s13178-0160254-9. 
(i.e. deviant criminal subjects). ${ }^{48}$ The early days of the sex workers' rights movement in the United States thus featured attempts by sex workers and activists to reclaim stigmatised labels so that they might have a language by which they could advocate for their rights. ${ }^{49}$ However, these efforts were largely superseded by the emergence of the language of 'sex work'-language which was created by a sex worker, and which was further propagated by those sex workers who did have access to hegemonic power. ${ }^{50}$

The development of the language of 'sex work' has thus been crucial to the development of the sex workers' rights movement. It opened the door for groups such as the International Labour Organization to recognise sex work as labour. ${ }^{51}$ It also helped reconceptualise how HIV researchers engage with and help deliver services to sex workers, which, in turn, created fora for sex workers to organise and rally for political changes. ${ }^{52}$ More recently, it has provided the conceptual framework for organisations like Amnesty International to call on states to respect, protect, and fulfil the rights of sex workers. ${ }^{53}$

The term 'sex trafficking', however, shuts down all these possibilities. It once again transforms sex workers from workers who can claim their rights into either criminal 'sex traffickers', subject to punishment, or else passive 'victims

48 See, for example, G Pheterson, 'The Whore Stigma: Female dishonor and male unworthiness', Social Text, vol. 37, 1993, pp. 39-64, https://doi.org/10.2307/ 466259; J Doezema, Sex Slaves and Discourse Masters: The construction of trafficking, Zed Books, London, 2010; H K Hallgrímsdóttir, R Phillips, and C Benoit, 'Fallen Women and Rescued Girls: Social stigma and media narratives of the sex industry in Victoria, B.C., from 1980 to 2005', Canadian Review of Sociology/Revue Canadienne de Sociologie, vol. 43, no. 3, 2006, pp. 265-80, https://doi.org/10.1111/j.1755618X.2006.tb02224.x; J A Koken, "The Meaning of the "Whore": How feminist theories on prostitution shape research on female sex workers', in M H Ditmore, A Levy, and A Willman (eds.), Sex Work Matters: Exploring money, power and intimacy in the sex industry, Zed Books, London, 2010, pp. 28-64.

49 Weitzer, 'Resistance to Sex Work Stigma', p. 5.

${ }^{50}$ C Leigh, 'Inventing Sex Work', in Jill Nagle (ed.), Whores and Other Feminists, Routledge, New York, 1997, pp. 225-32; K Kempadoo, 'Globalizing Sex Worker Rights', in K Kempadoo and J Doezema (eds.), Global Sex Workers: Rights, resistance and redefinition, Routledge, London, 1998, p. 8; F Delacoste and P Alexander (eds.), Sex Work: Writings by women in the sex industry, Cleis Press, Minneapolis, MN, 1987.

${ }^{51}$ L L Lim (ed.), The Sex Sector: The economic and social bases of prostitution in Southeast Asia, International Labour Office, Geneva, 1998.

${ }_{52}$ M H Ditmore (ed.), Encyclopedia of Prostitution and Sex Work, Greenwood Press, Westport, CT, 2006, pp. 208-209, 547.

53 Amnesty International, Amnesty International Policy on State Obligations to Respect, Protect and Fulfil the Human Rights of Sex Workers, AI, 2016, https:// www.amnesty.org/en/documents/pol30/4062/2016/en/. 
of sex trafficking', subject to forced rescue. If the sex industry is composed entirely of victims and perpetrators, then the only viable solution becomes police raids. The US Department of State, operating under the paradigm of 'sex work as sex trafficking', has long used its Trafficking in Persons (TIP) Report to push more developed countries, like Singapore, to use raids against their sex industries $;{ }^{54}$ in less developed countries, these raids are often funded and even directly managed by American religious organisations. ${ }^{55}$ This runs counter to much of the research on addressing human trafficking, since these raids-beyond the direct harm inflicted on the sex workers targeted for criminal sanction or forced rescue-can generate fear and distrust of law enforcement in vulnerable populations, making future cooperation against exploitative actors more difficult. ${ }^{56}$ This, in turn, leaves sex workers vulnerable to violent predation, and opens the door for violent organised crime groups to fill the governance void left by the state. ${ }^{57}$

The development and deployment of the term 'sex trafficking' is thus, in and of itself, a form of epistemic violence against sex workers. FOSTA, however, takes this epistemic violence one step further by rendering sex workers not only less able to speak to hegemonic culture, but also less able to speak among themselves. In part, it has done this by shuttering the social spaces previously used by sex workers. These have included not only major sites like Reddit but

54 B Chapman-Schmidt, 'Sex in the Shadow of the Law: Regulating sex work and human trafficking in Singapore', Asian Journal of Comparative Law, vol. 10, no. 1, 2015, pp. 1-21, https://doi.org/10.1017/asjcl.2015.1.

55 Empower, $A$ Report by Empower Chiang Mai on the Human Rights Violations Women Are Subjected to When 'Rescued' by Anti-Trafficking Groups Who Employ Methods Using Deception, Force and Coercion, Empower Foundation, Chiang Mai, 2003; G Soderlund, 'Running from the Rescuers: New U.S. crusades against sex trafficking and the rhetoric of abolition', NWS A Journal, vol. 17, no. 3, 2005, pp. 64-87; V Magar, 'Rescue and Rehabilitation: A critical analysis of sex workers' antitrafficking response in India', Signs, vol. 37, no. 3, 2012, pp. 619-644, https:/ /doi.org/10.1086/662698.

${ }^{56}$ M Ditmore, 'The Use of Raids to Fight Trafficking in Persons', Sex Workers Project, New York, 2009, http://sexworkersproject.org/publications/reports/ raids-and-trafficking/; M Ditmore and J Thukral, 'Accountability and the Use of Raids to Fight Trafficking', Anti-Trafficking Review, issue 1, 2012, pp. 134-48, https://doi.org/10.14197/atr.201218; A Ahmed and M Seshu, "We Have the Right Not to Be 'Rescued'...": When anti-trafficking programmes undermine the health and well-being of sex workers', Anti-Trafficking Review, issue 1, 2012, pp. 149-168, https://doi.org/10.14197/atr.201219; M Dottridge, 'Introduction', in Global Alliance Against Traffic in Women, Collateral Damage: The impact of anti-trafficking measures on human rights around the world, GAATW, Bangkok, 2007, pp. 1-27.

57 B Chapman-Schmidt, 'The Transnational Governance of Human Trafficking in Japan', PhD diss., Australian National University, 2017, pp. 34-40, https:// openresearch-repository.anu.edu.au/handle/1885/144231. 
also smaller sites like 'HungAngels', which, out of fear for potential liability, removed forums that had previously provided social spaces for trans sex workers. ${ }^{58}$ It has also led to the disappearance of social safety tools for sex workers, such as the 'JUST FOR SAFETY' screening tools offered by VerifyHim, which had previously allowed sex workers to discuss safety concerns and avoid abusive clients. ${ }^{59}$ Notably, the little existing empirical evidence on services like these suggests that they have had a positive impact on sex workers' safety. ${ }^{60}$ If this is correct, then by eliminating these spaces, FOSTA is causing direct harm to sex workers. It will be some time before this can be verified with empirical research but the initial reports are not promising. ${ }^{61}$ One sex worker-run blog states that:

The sex worker community online started to hear about workers going back out on the street and missing their check-in calls_-as of April 14th, just based on anecdotal data passed between us, 13 workers have gone missing and two have been confirmed dead. Two workers have been assaulted at gunpoint, and I can't even count how many other stories of rape and assault I've heard from people returning to or just learning the streets for the first time. One person has already taken their life because of this legislation. ${ }^{62}$

\section{Conclusion}

In the American legal system, 'sex trafficking' refers to the trafficking of sex, and not, as many assume, to the trafficking of human beings for the purpose of sexual exploitation. This has been a legal reality since the passage of the Trafficking Victims Protection Act in 2000, and it has subsequently led to the

58 A Zimmerman, 'Sex Workers Fear for Their Future: How SESTA is putting many prostitutes in peril', The Daily Beast, 4 April 2018, https:// www.thedailybeast.com/sex-workers-fear-for-their-future-how-sesta-is-puttingmany-prostitutes-in-peril.

59 Greene, 'EFF Sues to Invalidate FOSTA, an Unconstitutional Internet Censorship Law.'

6) S Cunningham, G DeAngelo, and J Tripp, 'Craigslist's Effect on Violence Against Women', Working Paper, November 2017, http://gregoryjdeangelo.com/ workingpapers/Craigslist5.0.pdf.

${ }^{61}$ See, for example, S Cole, 'Pimps Are Preying on Sex Workers Pushed Off the Web Because of FOSTA-SESTA', Motherboard, 1 May 2018, https:// motherboard.vice.com/en_us/article/bjpqvz/fosta-sesta-sex-work-andtrafficking; Siouxsie Q, 'The War on Sex Workers Needs to Stop Now', Rolling Stone, 13 April 2018, https://www.rollingstone.com/politics/politics-news/thewar-on-sex-workers-needs-to-stop-now-628335/.

${ }^{2}$ C Simon, 'On Backpage', Tits and Sass (blog), 25 April 2018, http:// titsandsass.com/on-the-death-of-backpage/. 
United States government using instruments such as the Trafficking in Persons Report to push foreign states to adopt prohibitionist legislation and harmful criminal justice practices. It has also had domestic consequences, allowing laws like the recently passed FOSTA, which broadly target consensual sex work, to be sold to the public as efforts to fight 'sex trafficking'. The propagation of the term 'sex trafficking' has thus become a form of epistemic violence that eliminates both the spaces and the very language used by sex workers to communicate with each other and with the general public. This epistemic violence, in turn, opens the door to increased physical violence against sex workers.

Researchers, including both academics and journalists, need to be particularly aware of this epistemic violence so that they can avoid participating in its propagation. This can be challenging, since, as Zimmerman notes, there is a 'moral consensus' on the issue of human trafficking: 'no one is "for" human trafficking. ${ }^{\prime 3}$ Bernstein (perhaps unintentionally) reinterprets this to argue that, "no one could plausibly claim to be "for sex trafficking" either" ${ }^{64}$ This, in turn, puts researchers in a bind. Goldman, for example, testified before both the US House of Representatives and the US Senate, arguing that FOSTA would harm sex workers and victims of human trafficking (as well as 'damage[ing] the Internet, perhaps radically'). ${ }^{65}$ Yet, in both cases, Goldman seemed to feel compelled to open his statements by observing that 'sex trafficking' was a 'horrific' and 'horrible' crime. ${ }^{66}$ However, if 'sex trafficking' is simply 'the trafficking of sex', then defining it as a 'horrible crime' suggests that a law like FOSTA might be entirely necessary - undermining everything that comes next in Goldman's testimonies. Likewise, Human Rights Watch has stated that, 'Sex work is based on adult consensual agreement. Sex trafficking is a horrific crime', ${ }^{67}$ again without seeming to be aware that 'sex work based on consensual agreement' is legally considered 'sex trafficking' in the United States. The same is true with media outlets, with reporters like Aja Romano, who provided an extensively researched overview of FOSTA for

${ }^{63}$ Y C Zimmerman, Other Dreams of Freedom: Religion, sex, and buman trafficking, Oxford University Press, Oxford, 2013, p. 21.

${ }^{64}$ E Bernstein, 'Militarized Humanitarianism Meets Carceral Feminism: The politics of sex, rights, and freedom in contemporary antitrafficking campaigns', Signs, vol. 36, no. 1, 2010, p. 46, https://doi.org/10.1086/651184.

65 Goldman, 'Sex Trafficking Exceptions to Section 230', p. 5.

${ }^{66}$ Goldman, 'Balancing Section 230 and Anti-Sex Trafficking Initiatives'; Goldman, 'Sex Trafficking Exceptions to Section 230'.

${ }^{67}$ S Wheeler, 'Why We've Filed a Lawsuit Against a US Federal Law Targeting Sex Workers', Human Rights Watch, 29 June 2018, https://www.hrw.org/news/ 2018/06/29/why-weve-filed-lawsuit-against-us-federal-law-targeting-sexworkers. 
Vox, presenting the term 'sex trafficking' uncritically and without a definition. ${ }^{68}$ While these researchers may personally use the term 'sex trafficking' as a shorthand for 'human trafficking for sexual exploitation', repeating it without exploring its legal meaning or critically engaging with it creates an atmosphere of definitional confusion. This, in turn, allows religious conservatives, for example, to recruit nominally progressive celebrities, such as the comedian Amy Schumer and the talk show host Seth Meyers, to appear in a public service announcement claiming that a law aimed at harming sex workers will instead help them. ${ }^{69}$

For any researcher or journalist concerned about the health and safety of sex workers, then, it is imperative to resist this epistemic violence. As a matter of principle, we should therefore avoid using the term 'sex trafficking' except when referring to specific policies such as FOSTA; in particular, the term should never be used as a shorthand for 'human trafficking for sexual exploitation'. Researchers and journalists should also not assume that politicians and policymakers calling for measures against 'sex trafficking' have the best interests of human trafficking victims at heart. Instead, these calls need to be viewed as efforts to target sex workers until or unless proven otherwise. Finally, researchers and journalists should push back against the propagation of these terms, and work to reopen both linguistic and social spaces for sex workers.

Ben Chapman-Schmidt is a recent PhD graduate of the Australian National University's College of Arts and Social Sciences' School of Sociology. His dissertation focusses on transnational human trafficking governance, using Japan's response to human trafficking as a case study. He was a visiting research fellow at Keio University, where he conducted research on human trafficking, sex work, and migrant exploitation with police, NGOs and government officials across Japan. He recently co-authored a major report on cyber-terrorism for the Korean Institute of Criminology, and is currently working on his first book, as well as looking into further research opportunities on human trafficking governance in East Asia. Email: ben.chapman-schmidt@anu.edu.au

68 Romano.

69 Mary Mazzio, PSA Featuring Seth Meyers, Amy Schumer, Josh Charles, Tony Shalhoub and Others - SESTA, accessed 9 July 2018, https://www.youtube.com/ watch?v $=9$ SB $7-$ uqvis 0 . 